\title{
A singular case of massive urethrorrhagia solved by transarterial embolization
}

\author{
Pane Francesco ${ }^{1 *}$ D, Coppola Milena ${ }^{1}$, Borzelli Antonio ${ }^{1}$, Giurazza Francesco ${ }^{1}$, Corvino Fabio ${ }^{1}$, Corvino Antonio ${ }^{2}$, \\ Silvestre Mattia ${ }^{1}$ and Niola Raffaella ${ }^{1}$
}

\begin{abstract}
Background: Urethrorrhagia is frequent in pelvic trauma, rarely due to traumatic injuries of internal pudendal artery branches.

Case presentation: Our aim is to underline the role of transarterial embolization in selected patients, as in this case in which a young man manifested urethral hemorrhage after high-energy motorcycle crash not associated with injuries of the inferior urinary tract. Multi-detector computed tomography (MDCT) showed pubic symphysis diastasis and perineal hematoma with pseudoaneurysm into the penis bulb. The first approach was conservative with perineal external compression and intravenous injection of tranexamic acid. Afterward, due to the decline of clinical conditions, we decided to perform a selective angiography, confirming the vascular injury of distal branches of both internal pudendal arteries with contrast agent extravasation into urethral bulb; endovascular embolization was performed with detachable micro-coils. The principal results were seen quickly, indeed urethrorrhagia arrested and hemoglobin values normalized. Erectile function was preserved at 6-months follow-up.

Conclusions: Endovascular embolization proved to be a minimally invasive therapeutic approach, clinically effective, with a low rate of complications and high probability to preserve erectile function.
\end{abstract}

Keywords: Urethrorrhagia, Internal pudendal artery, Endovascular embolization

\section{Background}

Urethrorrhagia is a clinical condition defined as a continuous or intermittent active bleeding from external urinary meatus, independent of urination, and so, it is different from hematuria; associated symptoms can be urinary burning or retention [1].

Its possible etiologies can be urinary stones, inflammations, infections, BPH, neoplasms, trauma, iatrogenic lesions, stenosis, diverticula, artero-venous malformations, and Klippel-Trenaunay syndrome [2-9] (Table 1).

The therapeutic approach for urethrorrhagia depends on the different cases and it can be conservative, urethroscopic, endovascular, or surgical $[1,10]$.

\footnotetext{
* Correspondence: dr.panef@gmail.com

'Interventional Radiology Department, AORN "A. Cardarelli", Via A. Cardarelli 9, 80131 Naples, Italy

Full list of author information is available at the end of the article
}

Urethrorrhagia due to pelvic trauma is more frequent in males and can manifest immediately or delayed [11]. In most cases, urethral traumatic lesions require a urologic approach, while rarely a vascular lesion (pseudoaneurysm or fistula) can be found in the correspondence of distal branches of the hypogastric artery (internal pudendal or obturator arteries). In these cases, a key role can be played by transcatheter endovascular embolization (TAE), representing a valid choice and mini-invasive effective treatment compared with other "invasive" approaches, ensuring a brief recovery time. In this article, we report and discuss the case of a young man with massive urethrorrhagia due to a pseudoaneurysm successfully treated with TAE thanks to prompt and correct management.

\section{Case presentation}

A 20-years-old man was admitted to our emergency department after a blunt perineal trauma from a high-

\section{Springer Open}

(c) The Author(s). 2020 Open Access This article is licensed under a Creative Commons Attribution 4.0 International License, which permits use, sharing, adaptation, distribution and reproduction in any medium or format, as long as you give appropriate credit to the original author(s) and the source, provide a link to the Creative Commons licence, and indicate if changes were made. The images or other third party material in this article are included in the article's Creative Commons licence, unless indicated otherwise in a credit line to the material. If material is not included in the article's Creative Commons licence and your intended use is not permitted by statutory regulation or exceeds the permitted use, you will need to obtain permission directly from the copyright holder. To view a copy of this licence, visit http://creativecommons.org/licenses/by/4.0/. 
Table 1 Causes of uretrorragia

\begin{tabular}{l}
\hline Calculus \\
Inflammatory process \\
Infection \\
Neoplasm (benign and malignant) \\
Benign prostatic hypertrophy \\
Trauma (contusive or penetrating) \\
latrogenic lesion (Foley insertion, urethra-cystoscopy, etc.) \\
Stenosis \\
Diverticulum \\
Arteriovenous malformation \\
Klippel-Trenaunay syndrome
\end{tabular}

energy motorcycle crash; he had no history of previous surgery or chronic medical therapy.

At his general physical examination, there was no fever and his hemodynamic status was hypotensive without tachycardia, he was referring to intense pelvic pain with normal urination but with blown continuous urethrorrhagia. Moreover, his perineal region was swelling and painful. In suspicion of a urethral injury, an epicystostomy was performed, but only normal urine was coming out from the bladder.

A MDTC examination after intravenous administration of contrast agent was performed, revealing a $15-\mathrm{mm}$ pubic symphysis diastasis, fractures of vertebral soma of the 5 th lumbar vertebra and of the distal left femoral epiphysis, and rectus abdominal muscles and perineal soft tissue hematoma, with no evidence of active bleeding (Fig. 1).

In this way, in the following hours, after a mechanical orthopedic stabilization of pelvis and blood transfusions, a retrograde urethrography was performed, excluding injuries to the lower urinary tract.

After 2 days, due to massive persistent urethrorrhagia and spread of pelvic hematoma until penis root and since it was not possible to perform an ultrasonographic perineal exploration due to his pain and physical pelvic conditions, MDTC examination was repeated, showing the presence of a pseudoaneurysm in correspondence of the penis bulb, characterized by early enhancement in the arterial phase of urethral corpus spongiosum (Fig. 2).

The first clinical approach was conservative with the application of a perineal compression and intravenous tranexamic acid administration; the conservative approach was due to the young age of the patient and pudendal artery district complexity, with many terminal branches.

In the following 3 days, a light but constant lowering of hemoglobin and hematocrit values happened with a concomitant increase of perineal hematoma with unchanged persistent urethrorrhagia; after a multidisciplinary consensus and informed consent by the patient, a pelvic angiography was performed. A Siemens Artis Zee

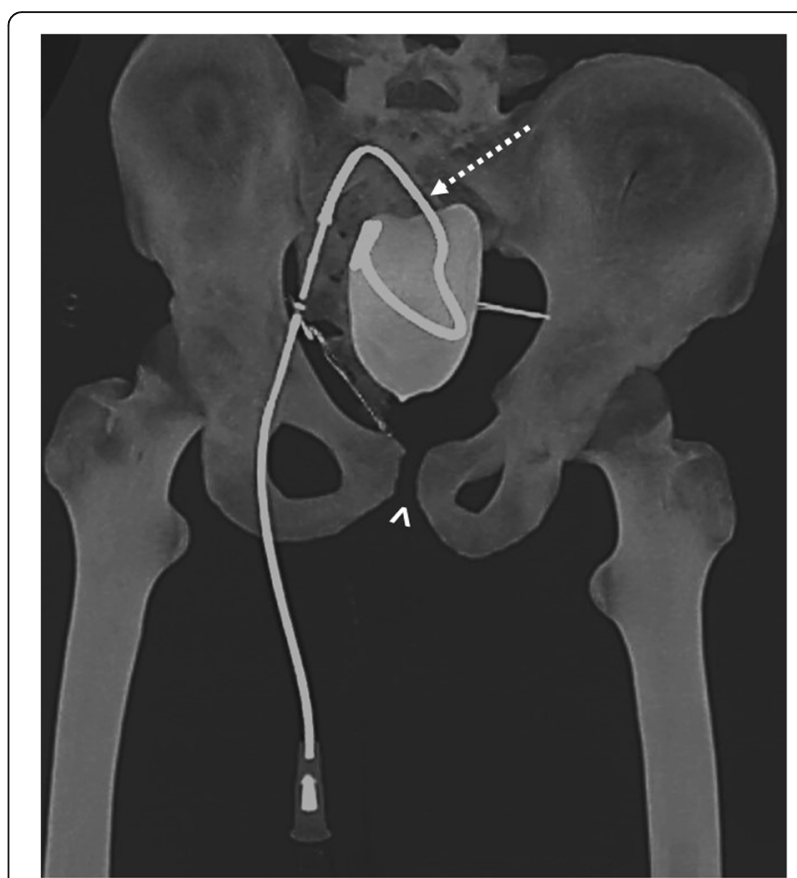

Fig. 1 Patient's conditions after admission to our hospital-MDTC 3D-MIP reconstructions showing pubic symphysis diastasis (head of white arrow) and epicystostomy (discontinued white arrow)

machine was employed, and after local administration of anesthesia (Mepivacaine 1\%), an US-guided common right femoral percutaneous arterial access was performed with $5 \mathrm{Fr}$ sheath (Terumo, Shibuya-ku, Tokyo, Japan) insertion.

The diagnostic angiography, performed with a 5 Fr pigtail catheter (Merit Medical, South Jordan, Utah) in abdominal aorta confirmed the presence of a vascular lesion of a pudendal artery distal branch, with a bilateral arterial supply.

Firstly, a coaxial ultra-selective microcatheterism of the target (bulbo-urethral) vessel was performed, under "road-map" guidance and employing a Progreat $2.7 \mathrm{Fr}$ (Terumo, Shibuya-ku, Tokyo, Japan) microcatheter, confirming active bleeding with opacification of the urethral bulb; the tip of microcatheter was positioned as closer as possible to the vascular lesion and an endovascular embolization was performed releasing detachable microcoils (Concerto, Medtronic B.V. Heerlen, The Netherlands). The final angiographic control with digital subtraction angiography (DSA) showed technical success with preserved physiologic "cavernosal blush" at the penis root (Fig. 3).

In the following second procedural step, a successful ultra-selective endovascular embolization was also performed of the contralateral pudendal artery branch, supplying the vascular lesion and the active bleeding (Fig. 4). The right common femoral arterial access was then sealed employing a closure device (Femoseal ${ }^{\circ}$, Terumo, Japan). 


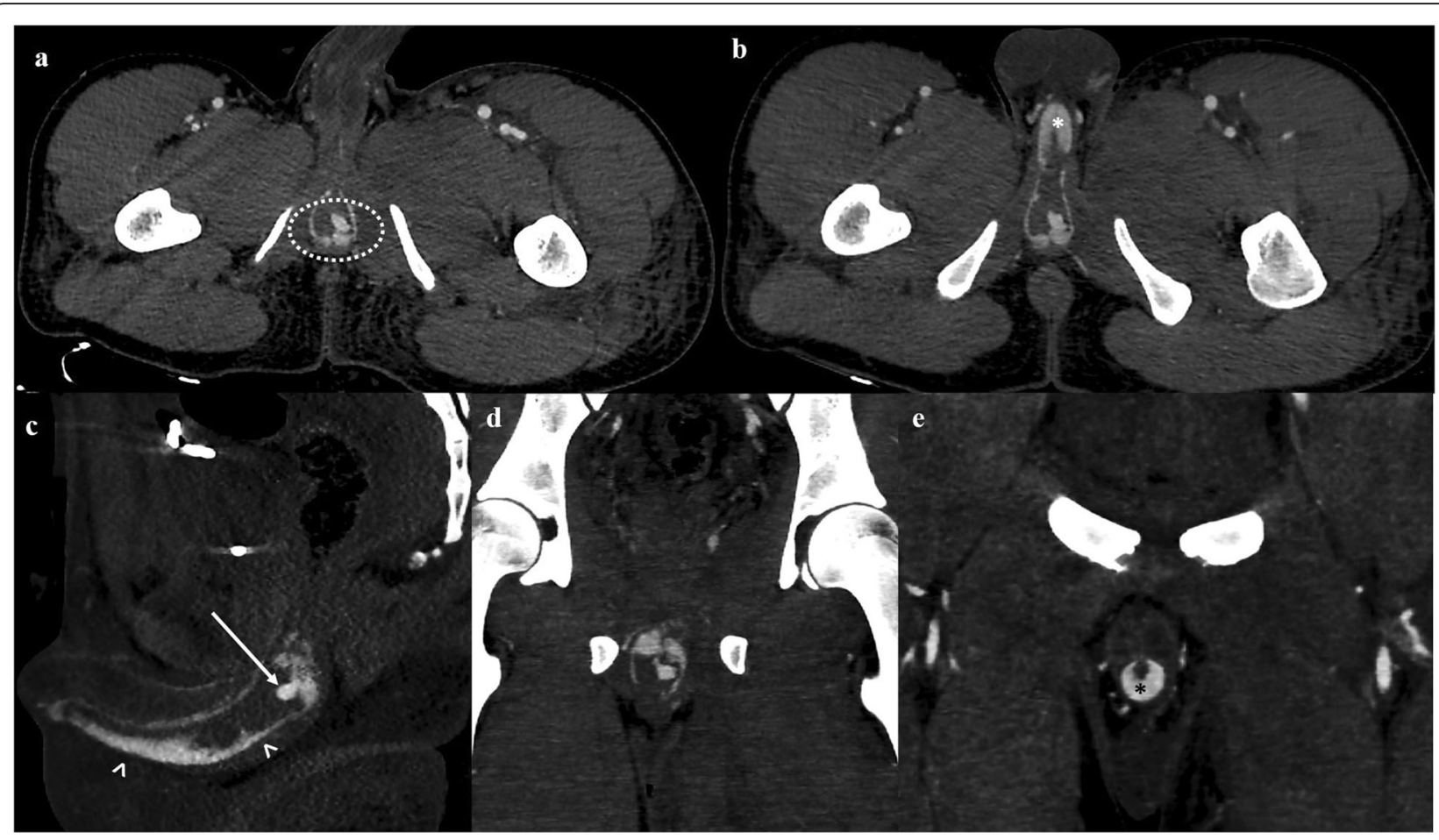

Fig. 2 MDTC, MIP reconstructions in the arterial phase (a) axial plane showing pseudoaneurysm at penis root (discontinued white oval); (b) axial scan showing early opacification of the penile body (white asterisk); (c) sagittal plane with vascular injury at penis root (white arrow) and contrast agent extravasation at third medium-distal of its inferior portion (head of white arrow); (d) coronal plane of the bulbar region showing clearly the pseudoaneurysm; (e) coronal plane showing early and intense opacification of urethral corpus spongiosum at the third medium portion of the penis (black asterisk)

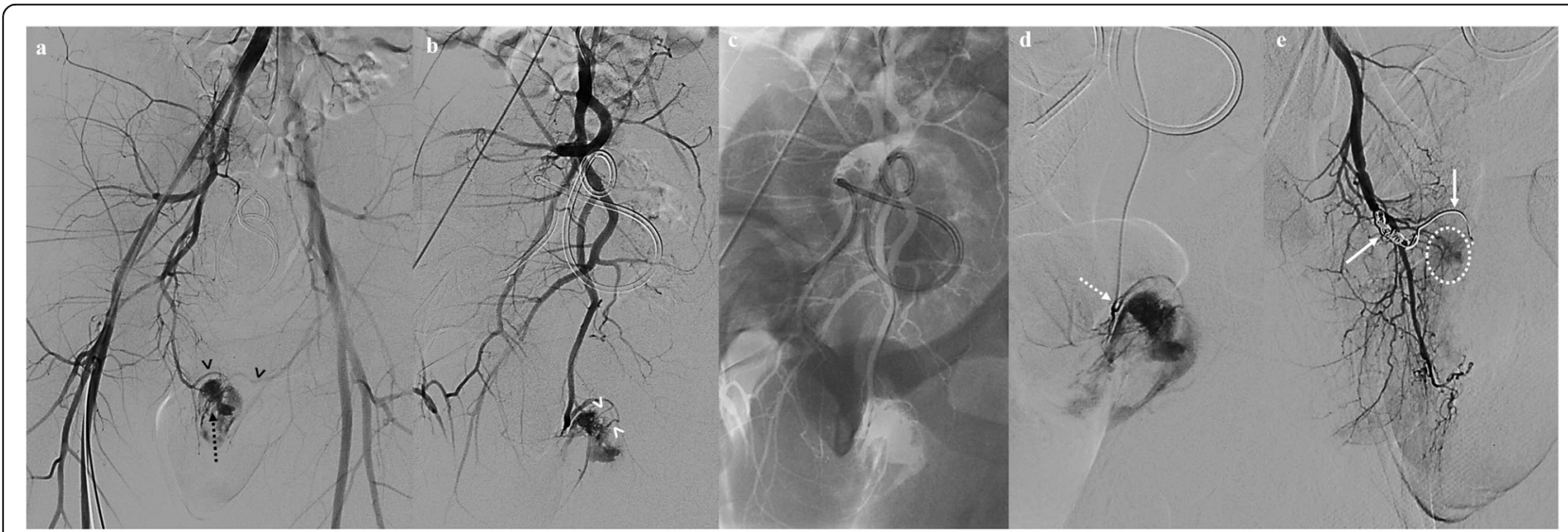

Fig. 3 Angiography, first procedural time: diagnostic angiography and endovascular embolization of right pudendal branches (a) digital subtraction angiography (DSA) with pig-tail catheter in abdominal aorta showing arterial active blush at penis root (discontinued black arrow) bilaterally supplied (heads of black arrows); (b) DSA of right hypogastric artery showing.urethral-bulb arterial branches (heads of white arrow), distal branches of the internal pudendal artery and localization of the vascular injury; (c) Ultra-selective microcatheterism of the target vessel under road-map guidance; (d) DSA showing contrast agent extravasation into the urethral bulb performed with microcatheter's tip at the origin ostium of the urethral-bulb arterial branch (discontinued white arrow); (e) DSA of the internal pudendal artery after endovascular embolization with micro-coils (white arrows), the vascular injury is successfully excluded and the physiological «cavernosal blush» (discontinued white oval) is preserved 


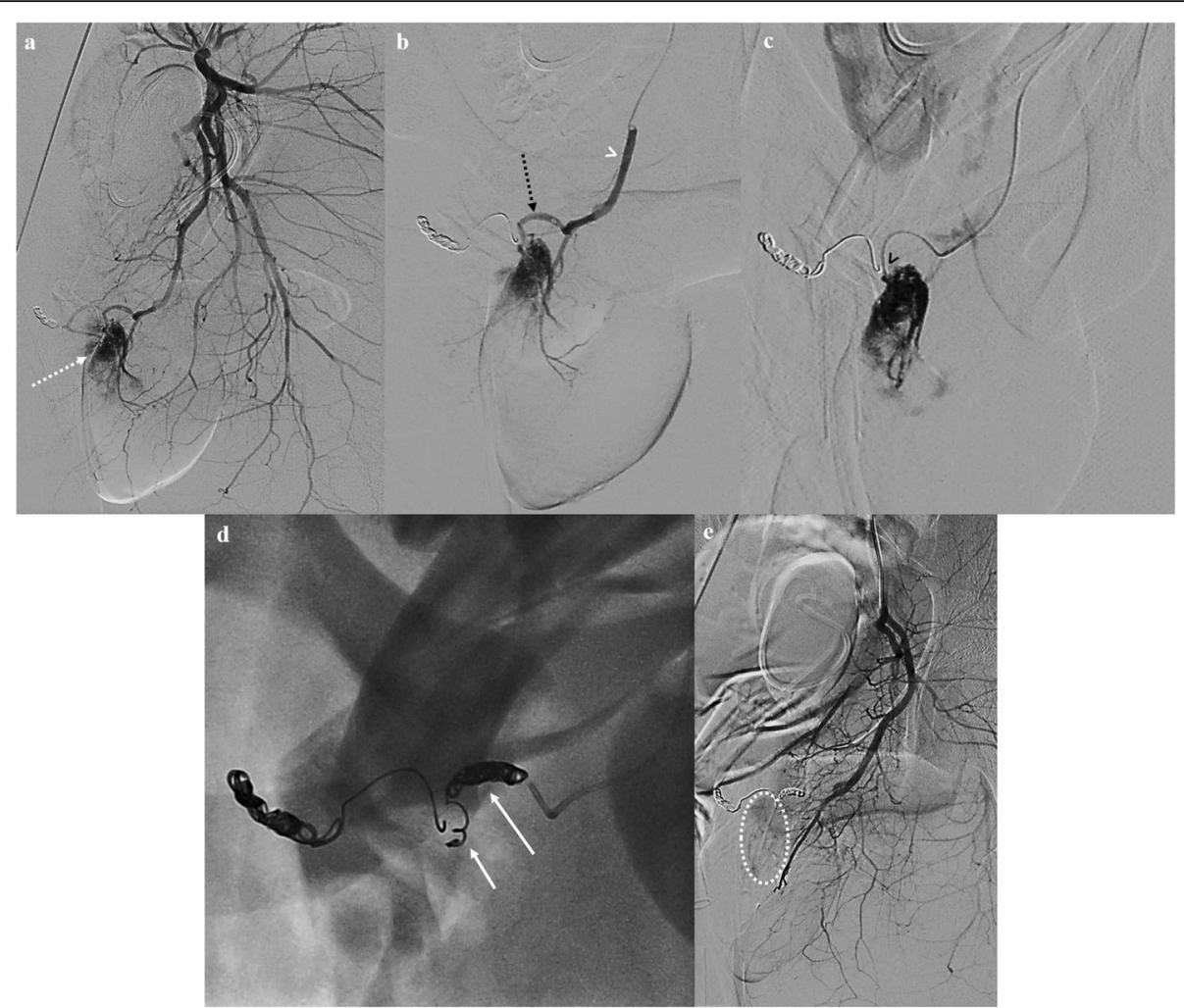

Fig. 4 Angiography, second procedural time: diagnostic angiography and endovascular embolization of right pudendal branches (a) DSA of left hypogastric artery branches showing vascular injury (discontinued white arrow) at the penis root supplied by a distal division branch of the left internal pudendal artery (discontinued white arrow); (b) DSA with microcatheter's tip at internal pudendal artery (head of white arrow) showing urethral-bulb branch (discontinued black arrow) with contrast agent extravasation; (c) microcatheter's tip is positioned as closer as possible to the vascular injury (head of black arrow); (d) fluoroscopy showing released micro-coils (white arrows); (e) DSA of the anterior branch of hypogastric artery showing successful embolization and presence of physiological «cavernosal blush» (discontinued white oval)

At the end of the procedure, urethrorrhagia immediately arrested because the source of bleeding was completely embolized, with hemoglobin values recovering in the following days without the necessity of further blood transfusions; as result of a target embolization, the patient referred normal urinary function and no erectile dysfunction, with preserved morning erections and normal sexual activity at 6-months follow-up (Fig. 5).

\section{Discussion}

Urethral injury is frequently due to motorcycle trauma, more frequent in males, where it can manifest with urethrorrhagia, penis and scrotal hematoma, penile or pubic branch fracture, and difficult urination [11, 12]. It can be defined by Goldman classification of urethral injury, which considers the type of trauma and the anatomical site involved, identified by imaging, in this way guiding the following therapeutic management [10].

Patients with suspected urethral injury should undergo, if possible, a retrograde urethrography [12], remembering that traumatic urethrorrhagia is not always due to a urethral injury [13].
The bulbar urethra, which is less mobile compared with its other tracts, can be compressed in high-energy trauma between the inferior pubic branch and external bodies [12] and, therefore, we thought that the reported vascular injury could be due to the energy and violence of the motorcycle crash.

Urethrorrhagia due to a traumatic pseudoaneurysm is an extremely rare event and it represents a potentially fatal event; when it involves one of the distal branches of the internal pudendal artery, it can manifest with penis hematoma and perineal swelling $[5,14,15]$.

In literature, 10 cases of urethrorrhagia successfully treated with endovascular embolization are reported, due to urinary catheterization, endoscopic or surgical procedures, neoplasms, different kind of trauma (motorcycle, extreme sport, horse riding); half of them was due to bilateral supply of arterial lesion and main angiographic sign described are pseudoaneurysms, fistula, and arterial blushes.

Conservative management, initial preferred approach in these patients, consisted in the administration of hemostatic drug and antibiotics, suspension of eventual anticoagulant and/or antiplatelet therapies, external 


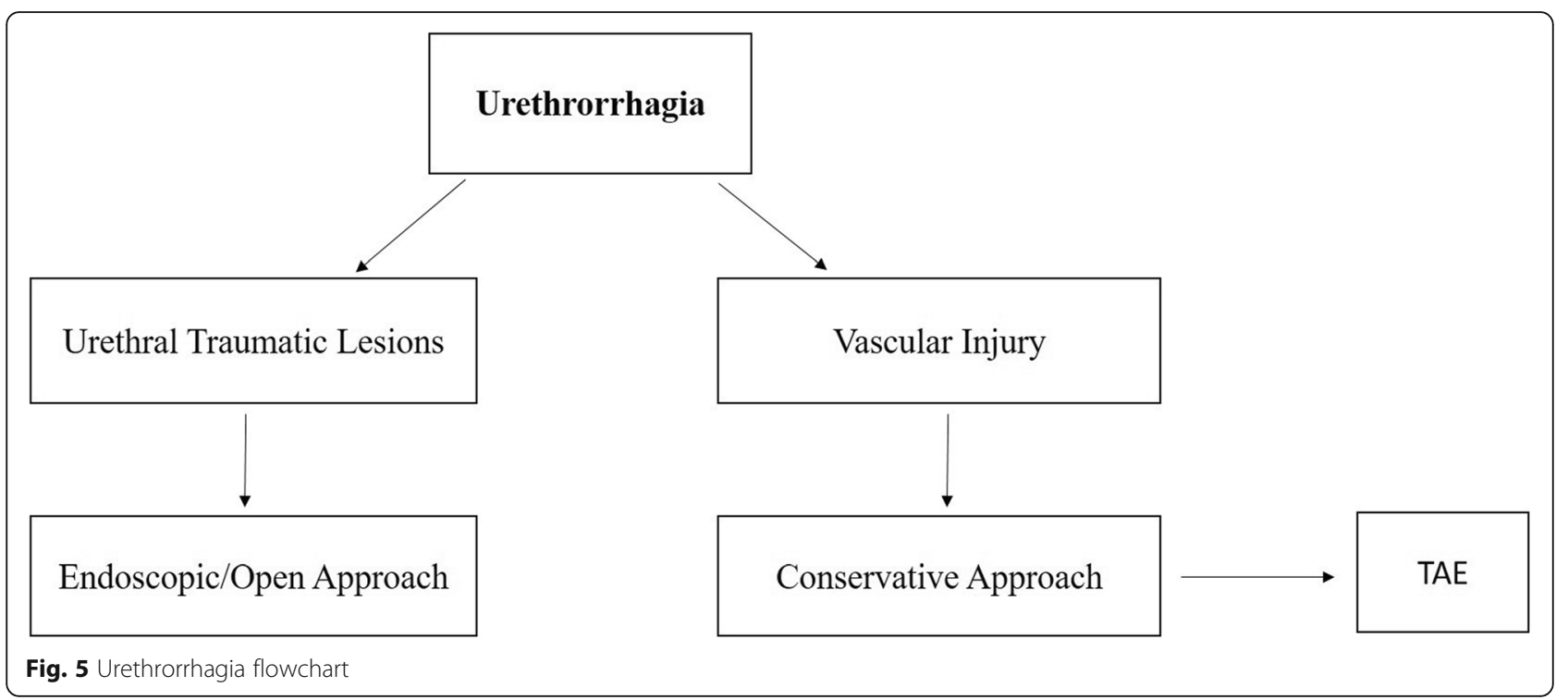

perineal or mechanical internal compression with urinary catheter; only after the failure of this first-line treatment, TAE could be considered and in the majority of cases, it revealed clinically effective, without significant short- and long-term complications [7].

In cases where urethral injury can be excluded by retrograde urethrography, an effective first-line strategy can be represented by urinary catheters, also of elevated caliber, as hemostatic therapy [9]. Particular attention has to be paid to Foley urinary catheters when there is a concomitant anticoagulant and antiplatelet therapy, as these patients have a higher risk of developing vascular lesions [9].

Another possible cause of urethrorrhagia, although less frequent, is the sexual activity named "urethral sounding", as described by Kwong where conservative management proved to be effective, discouraging the patient to keep on practicing it anymore [16].

Two singular and unique cases, both successfully treated by TAE employing autologous clots, are represented by a first patient with priapism due to surgical urethrotomy who manifested intermittent urethrorrhagia after every attempt to remove the urinary catheter [17] and a second patient with urethrorrhagia that was clinically evident only in case of penile erection. In the latter, it was necessary to perform a MRI of the penis, to precisely anatomically identify the tunica albuginea, urethra, and its corpus spongiosum, and allow a better definition and visualization of the injury to correctly plan the correct management [13].

Angiography proved that DSA allows in more than 50\% of cases to better identify the target vessel and the precise localization of active bleeding and extravasation of contrast agent, rather than conventional fluoroscopy, due to a better contrast resolution and proved, in addition, that sometimes the diagnosis can be missed owing for the lacked selectivity of the angiographic study performed [1].
The internal pudendal artery is fundamental for erectile function and so in order to preserve the patency of its arterial terminal branches is fundamentally performing a TAE with the tip of microcatheter as closer as possible to the vascular injury; this principle is important to avoid non-target embolization and to reduce at the minimum the risk of subsequent iatrogenic erectile dysfunction [18].

Since the complexity of perineal arterial district, the use of embolic agents, temporary or permanent ones, requires adequate experience and training by the operators $[1,19,20]$.

Sometimes, endovascular embolization of the bulbourethral artery can be indicated in recurrent hematuria as an alternative to manual compression and to electrofulguration [11].

The reported complications in the literature of endovascular embolization of internal pudendal artery for urethrorrhagia are rare: erectile dysfunction, urethral ischemia with associated stenosis [11]; after the reported experience of ischemia and necrosis of glans, Kim suggests to carefully control eventual change in color of glans itself [21].

Since there are too few cases reported in the literature, it is not possible to define with certainty if the simultaneous bilateral endovascular embolization of distal branches of both internal pudendal arteries can effectively influence erectile function [1].

Some authors state that it is not clear if endovascular embolization is really associated with erectile dysfunction, as the latter can be the clinical expression of a systemic vascular disease too, such as endothelial disfunction [9].

In our patient, we decided to perform TAE with detachable micro-coils because we thought that particles (either temporary or permanent) would not have been enough 
considering the entity of vascular injury, while a liquid one (such as $n$-butyl-cyanoacrylate) would not have guaranteed an adequate control during its injection; we excluded from our choices autologous clots because we think they are not effective, according to our experience, and outdated compared with other embolic agents available.

Owing to the considerable complexity of vascular and nervous structures in the perineal area and at the penis root, it is universally recognized that TAE represents a more effective solution to refractory urethrorrhagia rather than open surgery $[6,7,11,22]$. However, it is reported a case of massive urethrorrhagia due to an arterio-venous malformation successfully treated with surgical ligation with no complicancies [3].

\section{Conclusions}

Urethrorrhagia secondary to traumatic vascular injuries can be adequately managed by TAE when conservative approach fails; in contrast, open or endoscopic approaches are characterized by a less hemostatic effect and can increase vascular injury. These rare endovascular procedures should be carried out by well trained and experienced operators and due to a few cases reported in the literature, it is not possible to standardize the embolization technique.

\section{Abbreviations}

TCMD: Multi-detector computed tomography; TAE: Transcatheter endovascular embolization; DSA: Digital subtraction angiography

\section{Acknowledgements}

No acknowledgements are present.

\section{Authors' contributions}

FP is the main author who gathered the data, wrote the manuscript, and submitted it to the journal. The authors read and approved the final manuscript. $M C$ and $A B$ made substantial contributions to the design of the work; acquisition, analysis, and interpretation of data; drafted the work and revised it and approved the submitted version and agreed to be both personally accountable for the author's own contributions and to ensure that questions related to the accuracy or integrity of any part of the work, even ones in which the author was not personally involved, are appropriately investigated, resolved, and the resolution documented in the literature. FC made the acquisition, analysis, and interpretation of data and approved the submitted version and agreed to be both personally accountable for the author's own contributions and to ensure that questions related to the accuracy or integrity of any part of the work, even ones in which the author was not personally involved, are appropriately investigated resolved, and the resolution documented in the literature. FG made the acquisition, analysis, and interpretation of data and approved the submitted version and agreed to be both personally accountable for the author's own contributions and to ensure that questions related to the accuracy or integrity of any part of the work, even ones in which the author was not personally involved, are appropriately investigated, resolved, and the resolution documented in the literature. AC and MS drafted the work and revised it and approved the submitted version and agreed to be both personally accountable for the author's own contributions and to ensure that questions related to the accuracy or integrity of any part of the work, even ones in which the author was not personally involved, are appropriately investigated, resolved, and the resolution documented in the literature. RN made the acquisition, analysis, and interpretation of data and approved the submitted version and agreed to be both personally accountable for the author's own contributions and to ensure that questions related to the accuracy or integrity of any part of the work, even ones in which the author was not personally involved, are appropriately investigated, resolved, and the resolution documented in the literature. Each author has participated sufficiently in any submission to take public responsibility for its content. All authors have read and approved the manuscript. We confirm that this work is original and has not been published elsewhere nor is it currently under consideration for publication elsewhere.

\section{Funding}

No funding was received.

\section{Availability of data and materials \\ The data used and/or analyzed during the current study are available from the corresponding author on reasonable request.}

\section{Ethics approval and consent to participate}

The research involving human participants was approved by the ethics committee of the institution involved (AORN Cardarelli di Napoli) and written informed consent was obtained to participate.

\section{Consent for publication}

Written informed consent was obtained from the patient for publication of this case report and accompanying images.

\section{Competing interests}

The author declares that he has no competing interests.

\section{Author details}

"Interventional Radiology Department, AORN "A. Cardarelli", Via A. Cardarelli 9, 80131 Naples, Italy. ${ }^{2}$ Motor Science and Wellness Department, University of Naples "Parthenope", Via F. Acton 38, 80100 Naples, Italy.

Received: 8 June 2020 Accepted: 17 August 2020

Published online: 25 August 2020

\section{References}

1. Liu S, Deng J, Zeng B, Jia Y (2019 Jul) Embolization with microcoils for urethral hemorrhage: a case report. Medicine (Baltimore) 98(27):e16184. https://doi.org/10.1097/md.0000000000016184

2. Lei H, Guan X, Han H, Qian X, Zhou X, Zhang X et al (2018) Painless urethral bleeding during penile erection in an adult man with Klippel-Trenaunay syndrome: a case report. Sex Med 6:180-183. https://doi.org/10.1016/j.esxm. 2017.12.001

3. White JT, Baverstock RJ (2017) Eruption of blood: arteriovenous malformation of the penile urethra. Can Urol Assoc J 11:E32-E34. https:// doi.org/10.5489/cuaj.4131

4. Kondo H, Yamada T, Kanematsu M, Jia Y (2007) Embolization for massive urethral hemorrhage. Abdom Imaging 32:262-263. https://doi.org/10.1007/ s00261-007-9227-z

5. Huang TY, Huang CN, Lee YC (2013) Life-threatening urethral bleeding induced by a pseudoaneurysm of the obturator artery. Urology 82:e43-e44. https://doi.org/10.1016/j.urology.2013.08.016

6. Hoffer EK (2008) Transcatheter embolization in the treatment of hemorrhage in pelvic trauma. Semin Intervent Radiol 25:281-292. https:// doi.org/10.1055/s-0028-1085928

7. Chen J, Wang S, Wu D, Wu J (2015) Bilateral internal artery-urethral fistula formation by pseudoaneurysm. Acta Orthop Traumatol Turc 49:456-548. https://doi.org/10.3944/AOTT.2015.13.0037

8. Barratt RC, Bernard J, Mundy AR, Greenwell TJ (2018) Pelvic fracture urethral injury in males - mechanisms of injury, management options and outcomes. Transl Androl Urol 7(Suppl 1):S29-S62. https://doi.org/10.21037/ tau.2017.12.35

9. Hayashi Y, Kawashima A, Fujita K, Kato T, Abe T, Ujike T et al (2018 Jan 12) Selective arterial embolization for uncontrollable urethral hemorrhage in a patient with a left ventricular assist device. Urol Case Rep. 17:70-72. https:// doi.org/10.1016/j.eucr.2018.01.001

10. Goldman SM, Sandler CM, Corriere JN (1997) Blunt urethral trauma: a unified, anatomical mechanical classification. J Urol 157:85-89. https://doi. org/10.1016/s0022-5347(01)65291-1

11. Nadarajah J, Baliyan V, Yadav AK, Kumar A, Gamanagatti S, Saini A et al (2015 Apr) Traumatic pseudoaneurysm of bulbourethral artery managed by 
coil embolization. Indian J Surg. 77(Suppl 1):140-142. https://doi.org/10. 1007/s12262-014-1204-5

12. Hodge I, Adam A, Chennapragada M, Tiu A, Deshpande AV (2018 Apr) Traumatic urethraggia in adolescence: ushering in the new age of "extreme sports". Urology. 114:181-183. https://doi.org/10.1016/j.urology.2017.12.021

13. Shin YS, You JH, Kim MK (2015 Sep) A pseudoaneurysm of the corpus spongiosum from straddle injury: A rare cause of massive urethral bleeding only during erections. Injury. 46(9):1867-1869. https://doi.org/10.1016/j. injury.2015.02.027

14. José CS, Nicolás BP, Pablo AA, Vicente SZ, Juan Carlos BP, David CS (2016 Apr 22) Urethrorrhagia secondary to traumatic penile pseudoaneurysm. Urol Case Rep. 7:10-13. https://doi.org/10.1016/j.eucr.2016.03.009

15. Hanash KA, Al-Shammari M, Mokhtar AA et al (2002) Posttraumatic pseudoaneurysm of the pudendal artery successfully managed with embolization. J Urol 168:1498-1499. https://doi.org/10.1097/01.ju. 0000030921.86435 .24

16. Kwong T, Larner T (2012 May) A rare and unusual case of urethral bleeding. BMJ Case Rep. 30:2012. https://doi.org/10.1136/bcr-2012-6155

17. Tuygun C, Guvercinci M, Conkbayir I, Gucuk A, Imamoglu A (2007 Dec) Postsurgical high-flow priapism treated by embolization. Int J Urol. 14(12):11071108. https://doi.org/10.1111/j.1442-2042.2007.01895.x

18. De Magistris G, Pane F, Giurazza F, Corvino F, Coppola M, Borzelli A et al (2020 Mar) Embolization of high-flow priapism: technical aspects and clinical outcome from a single-center experience. Radiol Med. 125(3):288295. https://doi.org/10.1007/s11547-019-01113-w

19. Gómez AML, Santana PC, Mourão AP (2020) Dosimetry study in head and neck of anthropomorphic phantoms in computed tomography scans. Sci Med J 2(1):38-43. https://doi.org/10.28991/SciMedJ-2020-0201-6

20. Paranjape S, Singhania N . Effect of body positions on quadriceps angle measurement. Sci Med J. Vol. 1, No. 1, March, 2019. https://doi.org/10. 28991/SciMedJ-2019-0101-3

21. Kim TN, Lee CH, Baek SR, Lee KM, Choe S, Park NC (2018) Penile glans necrosis developing after internal pudendal arterial embolization: a case report. Urol J 15(2):61-63. https://doi.org/10.22037/uj.v0i0.3867

22. Radhakrishnan S, Marsh R, Sheikh N, Johnson P, Greene D (2005) Urethral catheter induced pseudoaneurysm of the bulbar artery. Int J Urol. 12: 922e924. https://doi.org/10.1111/j.1442-2042.2005.01176.x

\section{Publisher's Note}

Springer Nature remains neutral with regard to jurisdictional claims in published maps and institutional affiliations.

\section{Submit your manuscript to a SpringerOpen ${ }^{\circ}$ journal and benefit from:}

- Convenient online submission

- Rigorous peer review

- Open access: articles freely available online

- High visibility within the field

- Retaining the copyright to your article

Submit your next manuscript at $\boldsymbol{\nabla}$ springeropen.com 